\title{
EDUCAÇÃO AO REVÉS: INDÍGENAS E CAMPONESES MATO-GROSSENSES
}

\author{
BACK-TO-FRONT EDUCATION: THE INDIGENOUS AND PEASANT COMMUNITIES OF MATO GROSSO
}

\author{
EDUCACIÓN AL REVÉS: INDÍGENAS Y CAMPESINOS MATO-GROSSENSES
}

\author{
CONTE, Isaura Isabel ${ }^{1}$ \\ PEREIRA, Lisanil da Conceição Patrocínio² \\ AZINARI, Amanda Pereira da Silva ${ }^{3}$
}

\section{RESUMO}

Este ensaio aborda a temática da educação trazendo as especificidades dos povos indígenas e da educação do campo no estado de Mato Grosso. As reflexões apresentadas são oriundas de observações registradas a partir de vivências, experiênciase atividades desenvolvidas junto ao Laboratório de Estudos e Pesquisas da Diversidade da Amazônia Legal (LEAL) da Universidade do Estado de Mato Grosso (Unemat), campus de Juara. Busca-se dialogar com a educação popular devido a relação intrínseca que essas educações específicas sinalizam e, mais que isso se fazem nos contextos de seus surgimentos e desenvolvimento. Como pontos relevantes dessas discussões estão as resistências dos povos e populações que ousam fazer algo novo frente à política educacional, porém, tradicional pelo fato de que sempre fizeram suas educações com ou sem a presença de escolas. Tanto a educação escolar indígena quanto a educação do campo apresentam enormes desafios, entretanto suas existências não deixam se ser vitórias de lutas de muito tempo desses povos e populações.

Palavras-chave: Educação. Educação do campo. Educação escolar indígena.

\section{ABSTRACT}

This essay touches on the topic of education and the specificities of the indigenous people and field education in the state of Mato Grosso. The reflections presented come from observations made from experiences and activities developed together with the Laboratory of Studies and Research of Diversity in the Legal Amazon (LEAL) of the State University of Mato Grosso (Unemat), Juara campus. Interaction was sought with popular education due to the intrinsic link that these specific teaching signals and which, furthermore, form the contexts of their appearance and development. Relevant points of these discussions are the resistance of communities that dare to do something different to that set out in education policy but which is traditional due to the fact that they have always had their education with or without schools.Both indigenous school education and rural education present enormous challenges; however, their existence does not fail to be the victories of the long struggles of these peoples and populations.

Keywords: Education. Field Dducation. Indigenous school education.

\section{RESUMEN}

Este ensayo aborda la temática de la educación trayendo las especificidades de los pueblos indígenas y de la educación del campo en el estado de Mato Grosso. Las reflexiones presentadas son oriundas de observaciones registradas a partir de vivencias, experiencias y actividades desarrolladas junto al Laboratorio de Estudios e Investigaciones de la Diversidad de la Amazonía Legal (LEAL) de la Universidad del Estado de Mato Grosso (Unemat), campus de Juara. Se busca dialogar con la educación popular debido a la relación intrínseca que esas educaciones específicas señalan y, más que eso se hacen en los contextos de sus surgimientos y desarrollo. Como puntos relevantes de esas discusiones están las resistencias de los pueblos y poblaciones que se atrevan a hacer algo nuevo frente a la política educativa, pero tradicional por el hecho de que siempre han hecho sus educaciones con o sin la presencia de escuelas. Tanto la educación escolar indígena como la educación del campo presentan enormes desafíos, sin embargo sus existencias no dejan ser victorias de luchas de mucho tiempo de esos pueblos y poblaciones.

\footnotetext{
1 Universidade do Estado de Mato Grosso - Unemat - Mato Grosso - Brasil

2 Universidade do Estado de Mato Grosso - Unemat - Mato Grosso - Brasil

3 Universidade do Estado de Mato Grosso - Unemat - Mato Grosso - Brasil
} 
Palabras clave: Educación. Educación del campo. Educación de las escuelas indígenas.

\section{INTRODUÇÃO}

Neste ensaio apresentamos reflexões sobre a educação escolar considerando as especificidades dos povos indígenas e populações do campo em entrelaçamento com a educação popular. Afirma-se que vai ser tratado dessas educações como sendo ao revés, devido ao fato de nascerem de contestações, reivindicações e lutas de enfrentamento e, por isso se justifica trazer a educação popular. Essas educações, portanto, não nascem na escola, tampouco da escola, ao contrário: elas derivam das lutas que demandam a escola pública e de qualidade. Educações, no plural, é utilizado aqui, no mesmo sentido de Gadotti (2012) ao tratar de educação popular, educação social e educação comunitária, compreendidas como parte de um mesmo campo de luta, entretanto, contendo cada uma, sua especificidade.

As informações relacionadas ao contexto indígena e camponês são oriundas de inserção, estudos e pesquisas no Estado do Mato Grosso, compreendendo o período de 2015 a 2017, no território do Vale do Arinos, situado ao Noroeste do território Mato-Grossense. O texto, entretanto, é fruto de pesquisa participante e também pesquisa-ação com os devidos registros escritos e fotográficos, pois há inserção das autoras de forma direta em comunidades indígenas e camponesas. Isso implica em ações desenvolvidas conjuntamente com essas comunidades e povos, e, por vezes em intervenção no campo da educação e da cultura em aldeias e escolas do campo. Salienta-se que as atividades a que nos referimos são realizadas desde o grupo de pesquisa do Laboratório de Estudos e Pesquisas da Diversidade da Amazônia Legal (LEAL) da Unemat/Campus de Juara.

O trabalho que o LEAL vem desenvolvendo no Vale do Arinos e no Estado de Mato Grosso tem atendido demandas não só da pesquisa como da extensão universitária, pois, acreditamos no que ensinam Passos (2013) e Santos (2016a) de que a educação popular se entrelaça com a Cultura, com Arte e a Educação e, portanto, está além das escolas e universidades, embora não negamos a importância desses espaços. Salientamos, no entanto, que as atividades de pesquisa e extensão são definidas junto com as comunidades e povos indígenas, em diálogo com suas lideranças, pois se trata de uma relação de confiança construída durante alguns anos. Assim, a produção das reflexões se deu em estar junto, estar com, e observar, conversar, registrar, analisar e construir processos educacionais, culturais e de luta, de maneira respeitosa e não invasiva.

A imersão nas comunidades indígenas e do campo tem forte entrelaçamento aos projetos de pesquisas, extensão, elaboração de trabalhos de conclusão de curso, aulas de campo com os cursos de Pedagogia e Administração, participação de indígenas e camponeses/as nos eventos organizados ou apoiados pelo LEAL (Ex.: Mostra Científica e Cultural do Vale do Arinos, Kalunga, Festival Juruena Vivo, etc.), destacando que esta relação tem se estabelecido a partir de parcerias entre universidadecomunidade como possibilidades de fortalecimento das ações por elas desenvolvidas no âmbito da educação formal e não formal. 
As ações que desenvolvemos em educação e cultura, junto às comunidades indígenas da Terra Indígena Apiaká-Kayabi sãoestratégias no enfrentamento ao pensamento colonial, no sentido de valorização das diversidades étnicas e empoderamento do lugar. No território em questão habitam os povos Kayabi-Kawayweté, Munduruku e Apiaká, com seus conhecimentos que vem de "outras" fontes e, de certa maneira desestabilizam o pensar sobre educação, quando ela é compreendida somente como educação escolar "para todos", sem considerar culturas e modos de ser coletivos.

Desse modo, estar com esses sujeitos significa se posicionar, ter um lado na história, reafirmando uma educação popular e decolonial, tecendo sonhos e esperanças conforme acentua Santos (2016 b), quando nos ensina a reflexão sobre a utopia e sobre a sociologia das ausências na perspectiva da superação da linha divisória entre nós e eles. Nesse aspecto, a educação que defendemos e buscamos fazer e refletir não é neutra; ela denuncia e anuncia, visa transformar o que precisa ser transformado, não aceitando retrocessos de direitos. Tampouco, não dá para olhar para atrás como fatalismo e imobilidade considerando que

[...] as atrocidades puderam ser atribuídas às vítimas, os agressores foram condecorados por sua coragem na luta contra as agressões, os ladrões foram juízes, os grandes decisores políticos puderam ter uma qualidade moral minúscula quando comparada com a enormidade das consequências de suas decisões. Foi uma época de excessos vividos como carências; a velocidade foi sempre menor do que devia ser; a destruição foi sempre justificada pela urgência em construir (SANTOS, 2016a, p. 209).

Ao longo dos tempos tanto os povos indígenas quanto os camponeses foram considerados avessos ao progresso e à civilidade e, mais que isso: empecilhos para o desenvolvimento do progresso dos países no contexto da América Latina. Assim, educação escolar não fora pensada para esses povos e populações e, além disso, quando lhes fora oferecido, teve o sentido de lhes inserir no progresso almejado: um progresso bem distante de suas aspirações (CONTE, 2014). Frente às resistências e estranhamentos desses sujeitos com relação à escola, como algo que não pertencia aos seus universos socioculturais, foram, e em alguma medida ainda são tratados como desertores, evasores e culpados pelo fracasso. Nas palavras de Santos (Op. Cit.) fica evidente que foram tempos de excessos para alguns e, ao mesmo tempo, carência para tantos, que sequer eram contabilizados dos sensos populacionais, no caso do Brasil.

Nesse momento, a educação do campo e a educação escolar indígena garantidas oficialmente pelo Parecer $n^{\circ}$ 36/2001 e pela Resolução 05/2012, respectivamente, requer que se consiga fazer essas educações no sentido decolonial, para abrandar um pouco os equívocos, senão as violências cometidas. Na mesma direção, carregam a necessidade de fazer essa Outra educação para a construção daquilo que seja relevante a esses povos e populações em vista de elevar o seu saber, como afirma Brandão (1984); que seja respeitosa com as diversidades e não rasa e descontínua. 


\section{AS EDUCAÇÕES AO REVÉS: DESCONSTRUÇÕES E NOVAS TESSITURAS}

Não são poucos os referenciais teóricos afirmando que a educação escolar no Brasil foi um processo calamitoso, fragmentado, de negação etc., e, que devido a motivos políticos de dependência colonial não deveríamos ter mesmo acesso ao saber da leitura e da escrita, muito menos, ao saber considerado científico, mediante a compreensão da ciência válida europeizada, segundo Santos (2010). De acordo com Paiva (2003) foi no século XIX, no período imperial, que se deu início a um sistema educacional escolar muito incipiente, tratado pela autora como educação popular, sendo aquela destinada à população em geral. Entretanto, é somente da década de 1920 em diante que esse sistema educacional toma forma, oferecendo um maior número de escolas nas cidades e no campo.

A primeira forma de educação a que os brasileiros e as brasileiras tiveram acesso, foi aquela em que aprendiam tudo entre todos conforme afirma Brandão (1984) e, era educação popular praticada pelos indígenas antes da invasão colonial. Com a invasão, a educação necessária para esses povos foi a da contestação, da resistência, da luta com toda a força que pode ser empreendida. Por isso, de acordo com Paludo (2001), a educação popular no Brasil, surge desde as primeiras revoltasindígenas e na luta pela libertação dos escravos. Brandão (1984, p. 43) afirma que a educação popular é "escolar e extra-escolar, pública e alternativamente civil"; é aquela em que o povo, em seus processos de luta, eleva o seu próprio saber e, nesse aspecto se dá a inter-relação com a educação escolar indígena e com a educação do campo que tratamos nesse texto.

Quando passou a haver educação massiva para o povo, ela fora oferecida grandemente como escola de primeiras letras (anos iniciais do ensino fundamental) no campo, a partir de 1930, de acordo com Paludo (2001). Ferreira (2014), estudiosa da temática indígena no estado de Mato Grosso, assinala que a educação escolar indígena se deu com os jesuítas na perspectiva de uso da mão-deobra desses povos e no controle do território, desde a invasão colonial até o século XVIII. Assim, os aldeamentos e as missões jesuíticas mantinham os povos sob controle, ao passo que, os invasores circulavam levando raízes, plantas aromáticas e vegetais de seus interesses.

Segundo a mesma estudiosa pontua, até a década de 1970, a educação para os indígenas longe de ser a perspectiva desses - ficava sob controle de órgãos como o serviço de proteção ao índio (SPI) ou missões religiosas, cujo principal objetivo era a integração nacional. Com relação ao ensino nas escolas, os relatos da pesquisa mostram que era centrado na religião, na imposição cultural à base de violência física e no aprendizado da língua portuguesa, em geral, com a proibição de falarem a língua materna e de praticarem grande parte de seus costumes.

Corroborando com o tema, Stavenhagen (1988) assevera que a educação escolar indígena fora discutida pelo regime militar junto a política de aldeamentos, especialmente situados na região Amazônica, e, assim, criadas leis, a exemplo da 6.001 de 1973, que garantiriaa criação de uma escola em cada comunidade indígena. Em1979 ficou estabelecido pelo MEC que essas escolas seriam destinadas à adaptação de materiais didáticos.

Desse modo, podemos perceber os caminhos "tortuosos", mas, propositais da educação oferecida aos povos indígenas e às populações camponesas por serem, antes de tudo empobrecidos e, em grande medida considerados intrusos que "atrapalhavam" o desenvolvimento do país. Os

Reflexão e Ação [ISSN 1982-9949]. Santa Cruz do Sul, v. 28, n. 1, p. 34-48, jan./abr. 2020. 
indígenas tomados como selvagens e os camponeses como atrasados, mas ambos, no estereótipo preconceituoso, tidos como inconfiáveis, ignorantes, perigosos e carentes de civilidade. Quando organizados e mobilizados para lutar por direitos ou em defesa de território, são tidos como bárbaros e preguiçosos que não necessitam de terra; também como ameaçadores, manipulados por agentes externos, entre outras denominações.

Partindo das negações, seja por massacres ou devido ao tratamento que historicamente os excluiu do modelo tido como civilizatório, é que em seus processos de luta se colocam como sujeitos de direitos. Nesse aspecto, uma afirmação primeira é de que existem e, dessa maneira reivindicam coletivamente sua parte no estado dito democrático, inclusive se fazendovisíveis e existentes frente à Constituição Federal de 1988.

Para termos uma ideia, de acordo com o IBGE (2008), no Brasil os indígenas não eram considerados como tais no censo estatístico da população até o ano de 1991. No censo, eram descritos como caboclos ou variações assemelhadas e, assim deixavam de ser contabilizados, e, em alguns estados brasileiros dizia-se que não existiam esses povos. O rural, por sua vez, remetendo aos camponeses, também teve e tem seus prejuízos pela falta de uma definição mais precisa frente ao censo agropecuário até os dias atuais, segundo constatações de José Ely da Veiga em seus estudos, conforme aponta Wanderley (2011). Veiga aponta que no Brasil há descrição de povoados com menos de cinquenta habitantes, os quais são considerados vilas e, não espaço rural, por exemplo, o que faz "encolher" o número de territórios rurais, ao passo que, a urbanização avança consideravelmente nas estatísticas.

Ainda que tardio, vamos ter a educação do campo para os camponeses na atualidade e, educação escolar indígena para os povos indígenas como políticas públicas, mesmo que, ainda em construção e fortes embates ideológicos. A educação do campo surgira das lutas sociais na própria demanda e nos embates por acesso à terra, com especial destaque ao Movimento dos Trabalhadores Rurais Sem Terra (MST). De acordo com Caldart (2012) seu marco é o primeiro encontro nacional dos educadores da reforma agrária (I Enera), ocorrido no ano de 1997, sendo que esse encontro preparou a I Conferência Nacional de Educação (básica) do Campo. Na sequência, no ano de 2004, houve a segunda Conferência com aglutinação de muitas outras entidades representativas além das que já haviam participado em 1998. Essa educação

nomeia um fenômeno da realidade brasileira atual, protagonizado pelos trabalhadores do campo e suas organizações, que visa incidir sobre a política de educação desde os interesses sociais das comunidades camponesas. Objetivos e sujeitos a remetem às questões do trabalho, da cultura, do conhecimento e das lutas sociais dos camponeses no embate (de classe) entre projetos de campo e entre lógicas de agricultura que têm implicações no projeto de país e de sociedade e nas concepções de política pública, de educação e de formação humana (2012, p. 257).

Conforme podemos perceber, o conceito atual de EdoC é deveras avançado apresentando o embate de classes, superando a negação histórica da necessidade de uma educação específica, sendo que, o mesmo ocorreu com a educação indígena. Ambas têm origem nas reivindicações devido à falta de acesso, e num segundo momento, na forma de imposição de um sistema/modelo de 
desenvolvimento que os deixava à margem da sociedade. Por isso, o que thes fora oferecido precariamente, era educação para o meio rural e para os indígenas, sendo algo alheio aos seus contextos e suas necessidades.

A educação escolar indígena segundo Ferreira (2014) tem seu marco no estado de Mato Grosso no ano de 1898, junto a etnia Bororo com a primeira escola organizada por padres salesianos. Secchi (s/d) pontua que nesse caso, essa escola era disputada pelos órgãos de assistência como o SPI. De parte dos militares, a primeira escola indígena no estado fora fundada na primeira década do século XX na etnia Pareci. O estudo do Ferreira (Op. Cit.) nos mostra que, vai haver uma mudança nos rumos da educação escolar indígena no Brasil e, por sua vez no estado de Mato Grosso na década de 1970, inclusive com o importante papel do Conselho Indigenista Missionário (Cimi), criado no ano de 1970. Assim, em 1971, o Cimi deu início, em plena ditadura militar, à formação de missionários indigenistas com estudos antropológicos, por exemplo, garantindo um maior entendimento e respeitos a esses povos.

Em 1973, o então Estatuto do Índio garantia que se pudesse alfabetizar também na língua materna de cada povo e, nesse aspecto em muitos lugares nas aldeias deu-se a retomada da língua materna após décadas de proibição. A Constituição Federal de 1988 fora um avanço do ponto de vista legal aos povos indígenas, fruto da luta e organização pressionando por políticas específicas. $\mathrm{Na}$ mesma direção é que a Lei de Diretrizes e Bases (LDB) 9394/96 também veio a estabelecer a especificidade da educação indígena e para as populações rurais.

$\mathrm{Na}$ atualidade, após a criação da Secretaria de Educação à Distância, Alfabetização e Diversidade (Secad) no ano de 2004, transformada em Secretaria de Educação Continuada, Alfabetização, Diversidade e Inclusão (Secadi) em 2011, a educação indígena, passou a ter outro marco legal fundamental por meio da Resolução 05/2012 do MEC/SEB. Esta Resolução remete à Conferência de educação escolar indígena ocorrida no ano de 2009 frente aos territórios etnoeducacionais. Dá destaque à educação bilíngue de caráter multicultural com valorização dos conhecimentos tradicionais. A educação escolar indígena "deve se constituir num espaço de construção de relações interétnicas orientadas para a manutenção da pluralidade cultural, pelo reconhecimento de diferentes concepções pedagógicas e pela afirmação dos povos indígenas como sujeitos de direitos" (MEC/SEB, 2012, p. 03). Estabelece princípios como:

Art. $3^{\circ}$ Constituem objetivos da Educação Escolar Indígena proporcionar aos indígenas, suas comunidades e povos: I - a recuperação de suas memórias históricas; a reafirmação de suas identidades étnicas; a valorização de suas línguas e ciências; II - o acesso às informações, conhecimentos técnicos, científicos e culturais da sociedade nacional e demais sociedades indígenas e não-indígenas. (...). IV - a exclusividade do atendimento a comunidades indígenas por parte de professores indígenas oriundos da respectiva comunidade. (...) Art. $5^{\circ} \mathrm{Na}$ organização da escola indígena deverá ser considerada a participação de representantes da comunidade, na definição do modelo de organização e gestão (...).

Conforme podemos perceber essas educações específicas que ora aqui tratamos partem de lutas de povos e populações e buscam afirmar suas identidades junto à cultura e ao trabalho, que por 
sua vez, não são descolados ou deslocados de territórios. Assim o conceito de território deve ser entendido muito além do que espaço de terra para cultivo. Bello (2004) faz a diferenciação entre terra e território apontando que, terra é um meio de produção e, território é referente à identidade coletiva, étnica, havendo assim identificação simbólica, não só material. No mesmo sentido, Stavenhagen (1988) aborda território como regras de convivência, comportamentos, religiosidade, coesão social, incluindo sistema de parentesco e organização comunal/comunitária. Nesse aspecto, fica nítido o sentido coletivo e comunal negando o individualismo na origem dessas educações. Logo: trata-se de educação com sentido próprio para povos e populações que a reivindicaram e a forjaram na política pública.

Grosso modo, a pesquisa nos mostra que, se a educação escolar não for capaz de ensinar algo necessário/importante para a vida dos educandos indígenas e dos camponeses ela se torna fútil e é difícil de aguentá-la. Quando nesses fazeres específicos educacionais escolares se faz mera educação rural urbanizada e copiada para os contextos indígena e camponês, os educandos/as tendem a não suportar - e, a esse processo - de resistência - é dado o nome de evasão. Talvez a expressão que melhor ilustra esse fato é trazida por Charlot (2013) ao afirmar que esses sujeitos não evadem, pois sequer adentraram à escola; eles chegaram na escola mas não conseguiram embarcar nela. Foram expulsos na chegada, pois, se tratava de um universo tão incompreendido que parecia um outro mundo.

Dentre os estudos da didática escolar, em se tratando da educação geral ou genérica, Libâneo (1994) não se cansa de afirmar sobre a importância da educação ser contextualizada, respeitando os saberes e a cultura dos educandos. Essas afirmações corroboram com estudos de Pimenta (2002), que aponta o mesmo desde o final dos anos de 1980, mas quando, a partir de suas conferências, os povos indígenas e as populações camponesas/da agricultura familiar fizeram suas exigências em vista de políticas específicas, esse fato causou certo espanto. Para setores conservadores era como se eles estivessem reivindicando algo que estava causando cisão, além de ser desnecessário, uma vez que já estariam contemplados na oferta da educação pública e nos documentos oficiais como na LDBe no Plano Curricular Nacional (PCN).

A educação específica para esses povos e populações não quer dizer que devam ficar em seus universos afastados, ao contrário, trata-se de reforçar e, em alguns casos, reconstruir identidades e lutas, para se colocarem como sujeitos de direitos na sociedade, mostrando quem são e o seu protagonismo. É uma questão de exigência de respeito em tempos em que tanto se argumenta sobre a pluralidade e respeito às diferenças. Nesse ponto, busca-se aprender saberes desde as suas comunidades e também recuperá-los, diante das invasões territoriais, culturais e pedagógicas de tanto tempo.

O que percebemos desde as nossas pesquisas e registrosao estar com os sujeitos indígenase camponeses em suas escolas, é que essas educações demandam outro tempo e não tanto o tempo cronológico, pois se aprende o que é importante em todos os espaços de convivência. Assim sendo, o sentido de educação no plural é porque, além de ser algo específico de populações camponesas e 
povos indígenas, cada povo indígena, e as comunidades camponesas em sua diversidade de jeitos de se fazer pelo Brasil, possuem processos histórico-culturais, mitos, crenças, saberes e conhecimentos que perpetuam ou desconstroem, diferentemente, aspectos enquanto educação para si, indo muito além da educação escolar.

Em nossa convivência participante destacamos que o tempo pedagógico deve incluir as festas de santo, festas de colheita, de receber visitas/parentes; tempos para chorar, exclamar e bendizer os mortos; de tirar mel e madeira na lua certa; colher material para artesanato; tempo de plantio, de coivara; caçada; pescaria; tempo para rezas, curas, pajelança, benzimentos, nascimentos e, dessa forma, o calendário escolar pensado por não indígenas e por não camponeses pouco tem a dizer sobre os seus modos de ensino-aprendizagem.

Para as crianças sempre é tempo de brincar livremente nos rios, subir em árvores, se balançar nos cipós e redes, aprender a caçar animais pequenos e a flechar peixes. Tempo para se pintar e para saborear frutas silvestres. Tempo de fazer fogueira e assar peixe na vara. Tempo de aprender tudo com os adultos e com todos os parentes. Tempo de rir e de conhecer cada palmo do lugar e, tudo isso é a Escola da aldeia, do rio, do mato, dos espíritos da mata e dos animais.

Junto às aprendizagens pedagógicas está a luta pela defesa do território, conforme afirmava uma liderança e professora indígena, enfatizando que os indígenas, estando ou não em territórios demarcados pelo Instituto de Nacional de Colonização e Reforma Agrária (Incra) sofrem pressão constantemente por parte de fazendeiros e arrendatários que cobiçam seus espaços em nome dos lucros do agronegócio. Trata-se do conflito entre o bem-viver e o agronegócio, tido como progresso de todos e para todos. Não obstante, conforme denuncia Stavenhagen (1988), a Fundação Nacional do Índio (Funai), como órgão público de proteção aos indígenas, foi em muitas ocasiões, utilizada por fazendeiros para deslocar forçadamente indígenas em favor de projetos de mineração, criação de gado e construção de hidrelétricas.

No caso das escolas rurais, o fechamento de milhares delas na década de 1990 , de forma especial, se deu pelo mesmo motivo. Primeiro houve expulsão das famílias camponesas, de diversas formas, incluindo violência, falta de política pública, acesso às escolas, entre outros fatores, visando liberar terra para ampliação de granjas e fazendas. O que confirma esse fator, embora escondido no chamado "êxodo rural", como se fosse um desejo das famílias, que deixadas em péssimas condições, não restava outro caminho a não ser a migração forçada, são os altos índices de conflitos agrários no campo brasileiro4.

Nossas observações mostram que nas escolas indígenas da região Noroeste do estado de Mato Grosso, há uma grande confluência dos tempos da comunidade com os tempos pedagógicos, não havendo grande cisão. $\mathrm{O}$ fato dos professores serem todos indígenas tem sido bastante positivo, pois entendem da vida, da cosmovisão e da resistência da aldeia. As crianças e os anciãos participam da vida da escola no sentido de que há liberdade para entrarem e saírem no espaço escolar quando

\footnotetext{
${ }_{4}$ Para maiores informações, pode-se consultar como fonte a Comissão Pastoral da Terra (CPT) que tem se dedicado a acompanhar e a publicar o mapa dos conflitos agrários no Brasil.
}

Reflexão e Ação [ISSN 1982-9949]. Santa Cruz do Sul, v. 28, n. 1, p. 34-48, jan./abr. 2020 https://online.unisc.br/seer/index.php/reflex/index 
quiserem e, muito raramente se percebe crianças estressadas, chorando ou sendo repreendidas ao estarem com os adultos nas atividades ou na escola.

Não há muros e cercas nem na escola, nem no cemitério, tampouco ao redor das casas ou, ainda, proibições das crianças irem ao rio. Esse já é um sentido ao revés da educação que ocorre, não em local separado chamado sala de aula, embora ela exista. Na educação escolar indígena, embora se utilizam materiais pedagógicos do MEC, os muitos artefatos feitos por eles mesmos, não são deixados de lado, inclusive as pinturas no corpo e as histórias de seus antepassados com os mitos de origem de seus povos. Os locais sagrados, os roçados, o extrativismo, as pescarias e as festas são incluídas no calendário escolar, ultrapassando assim os dias "santos" cristãos. O xamanismo é apreendido com os anciões da própria aldeia ou com outros parentes quando necessário.

Os mitos e a religiosidade cristã convivem lado a lado, mas, seria preciso uma pesquisa mais aprofundada para podermos afirmar como convivem ou, quais os embates. O que se percebeu foi um profundo respeito frente às decisões familiares, pois diante de uma decisão de enterrar um ente querido dentro da casa e não no cemitério, por exemplo, há uma incidência na coletividade e assim, as crianças concebem o que pode ser feito, o que é tradição.

[...] se articulam ativamente os universos sociais e simbólicos das trocas de saber em comunidades rurais. Como, entre camponeses, existem situações e estruturas apropriadas de criação, de legitimação interna e de circulação e reprodução de diferentes tipos de conhecimento, valores de classe, símbolos, significados. De que modo ordens populares de trabalho pedagógico relacionam-se com as práticas do educador popular. Portanto, fundamentadas na práxis histórica de Paulo Freire, apostamos na dialogicidade entre vidas, percursos profissionais, conhecimentos e experiências, como alternativa de pesquisa e de formação de educadores, que possa servir à humanização de todos, às relações de igualdade, ao crescimento que se faz pela comunicação, à transformação das pessoas e dos contextos.

Com relação às escolas do campo, nem todas se dizem e seguem a política de educação do campo, por questões ideológicas ou por falta de acesso e entendimento do que muda entre a educação rural urbanizada, que sempre houvera ao longo dos tempos, e a proposta de educação do campo atual. Muitas dessas escolas já nucleadas têm uma diminuição significativa de alunos por conta da situação de migração forçada do campo, em especial, por falta de terra e trabalho digno, e, mesmo por causa da redução do número de filhos por família.

A escola nucleada de outrora é o que sobrou de dez ou mais escolinhas existentes nas linhas e vicinais, que com o esvaziamento programado para o campo "foram engolidas". Nesse momento, as escolinhas rurais ou são ruínas, ou, desapareceram completamente havendo poucas marcas, em geral perto de uma igreja. Nossas observações mostram que as escolas, de modo geral foram demolidas, mas as igrejas continuam em pé, mesmo que abandonadas. Que sinal seria esse?

A relação escola do campo e educandos é muito próxima, segundo observamos e, por sua vez, a figura do professor/a, bastante respeitada. Ainda é possível viver um outro tempo, menos ditado pelo relógio, em que é possível ouvir os alunos, saber o que está acontecendo com cada um e com suas famílias, e, assim como na educação indígena, a solidariedade é um laço forte, quase que obrigatório. 
Segundo nossas observações e escuta de relatos, a escola do campo se configura em um lugar tranquilo pelo fato de todos se conhecerem, das relações de parentesco e, das rezas comunitárias além do contato direto com a natureza.

O vínculo escola do campo e comunidade possibilita a articulação das pessoas dessa comunidade sendo um elo de coesão, de convivência, de aprendizado da cultura e das tradições locais, além de ser o espaço próprio de aprendizagens. A falta de terra ou o pouco espaço territorial das famílias, entretanto, é um dos dilemas percebidos pelos professores, jovens e suas famílias. problema da migração dos jovens é discutido, mas, foge a alçada da escola do campo e, por isso os professores afirmam que ensinam coisas importantes da vida do campo, mas também preparam os jovens para o Exame Nacional do Ensino Médio (Enem).

As questões da centralidade da vida e da sobrevivência, também dos sonhos das crianças e jovens atravessa diretamente as questões pedagógicas das escolas do campo e não há como fazer de conta que isso possa passar batido. Nesse caso, a relação com o universo urbano é maior, se comparado com a educação escolar indígena. Ambas modalidades de educação, no entanto, não são locais intocáveis e, não defendemos que deveriam de ser algo "puro" porque isso não é possível nos tempos atuais.

Conforme afirma Passos (2010) a cultura é cambiante e construída nas relações sociais, portanto, escolas indígenas e do campo estão imersas nessa cultura, são influenciadas por ela, ao mesmo tempo em que colocam também as suas questões, inclusive, políticas. O que defendemos é que a educação escolar indígena e do campo precisam ser fortalecidas com políticas públicas, com formação de professores desses locais para atuarem com a devida competência e respeitando essas especificidades. Nas escolas indígenas pesquisadas, situadas no território Apiaká-Kayabi, a maioria dos professores da aldeia não possuem ensino superior ${ }^{5}$ por falta de acesso, embora houve progresso nos últimos anos, pois na década de 1990, a maioria dos professores indígenas possuíam como formação o ensino fundamental, ou as escolas eram dirigidas por professores não indígenas.

Nessas duas modalidades educacionais os embates políticos estão sempre presentes, seja por conta da negação da especificidade que precisa ser respeitada, seja por conta da disputa de território material, nesse caso acesso à terra, uma vez que os conflitos não têm sido poucos. Logo: somente políticas educacionais isoladas não bastam para a construção da educação escolar indígena e do campo. É notório que as práticas de educação popular são vivas e vividas nos cotidianos dessas escolas e que, adentram nelas nas realidades indígena e de educação do campo. Muitos saberes e fazeres da comunidade são presentes nas escolas e, assim, pode-se acreditar em uma educação no sentido da formação humana, sempre com enormes desafios.

\footnotetext{
${ }^{5}$ Boa parte dos/as docentes foram formados no Projeto Tucum, modalidade específica para atender formação em nível de magistério de professores/as indígenas no estado de Mato Grosso entre o período de 1995 a 1999. Mais recentemente, há professores/as formados/as ou em formação pela Faculdade Intercultural Indígena (FAIND) da Universidade do Estado de Mato Grosso, no campus de Barra do Bugres, que atende especificamente povos indígenas em suas necessidades e potencialidades formativas. A referida Faculdade é coordenada por uma professora indígena, docente da Unemat e membra do LEAL.
}

Reflexão e Ação [ISSN 1982-9949]. Santa Cruz do Sul, v. 28, n. 1, p. 34-48, jan./abr. 2020 https://online.unisc.br/seer/index.php/reflex/index 
No momento atual, situando 2016-2018 com os cortes orçamentários profundos sofridos na educação brasileira, em especial na Secadi, que era responsável por prover e promover educação em vista da inclusão e da diversidade, incidindo diretamente às populações do campo e povos indígenas, a educação escolar indígena e a educação do campo passam por problemas. Pode-se afirmar, que recém estavam sendo vislumbrados as problemáticas dessas especificidades na tentativa de construílas, e, repentinamente, a diminuição de recursos financeiros, de material e de pessoal, desde a esfera federal afeta diretamente as secretarias estaduais e municipais. Assim, na região Noroeste de Mato Grosso, nossa pesquisa mostra a diminuição do atendimento a essas escolas por parte do Centro de Formação de Professores (Cefapro). O que se percebe é que há retrocesso e, ao que parece o povo mais uma vez é conclamado a "dar o seu jeito", ao passo que a precariedade vai aumentando. Volta-se a lutar por questões básicas que acreditava-se estar superadas.

\section{ALGUMAS CONSIDERAÇÕES}

Ao que nos mostra a pesquisa-inserção, a educação escolar indígena e do campo rompem com muito da educação tradicional-escolar evidenciando acima de tudo, que a vida do povo, do seu povo, é importante e, dele deriva uma série de aprendizagens e aprendizados.Por esse motivo, tratamos das educações evidenciando que conhecimento escolar é apenas um entre os tantos que dão sentido à vida daquelas pessoas.

Tratamos da educação ao revés, evidenciando que são várias e partem não da escola como central, mas do território em vários aspectos: território como espaço geográfico de terra; de contestação; de resistências; de insurgências; de novas experiências e práticas e, desde estes locais nasce a escola. Assim, a existência da escola deve ser com o povo e não para o povo. É uma educação entre, e, entrelaçada aos costumes, tradições e refazimentos culturais.

Para Ferreira (et. al. 2014, p. 01) 'mencionar 'conosco' é dizer da coletividade das decisões dialogicizadas e dialetizadas nos conflitos, nos desejos, nas dificuldades e na realização de cada ação, ancoradas na pedagogia popular que nos ensina Paulo Freire". Desse modo, a educação escolar indígena e a educação do/no campo precisam ser feitas com - conosco - comunidades, escolas e pesquisadores(as) contribuindo para o fortalecimento e para estratégias de sobrevivência e permanência da autonomia conquistada a duras penas.

Conforme aponta Bandão (2002, p. 99) "[...] educação popular encontra um sentido renovador, para colocar os seus instrumentos de reflexão e capacitação de pessoas e grupos cuja ação tornada movimento é mais do que nunca o determinante de uma educação [...]". A rede vem sendo tecida ao revés, coisa que somente as populações do campo e povos da floresta sabem fazer e nos ensinam com suas teimosias... muitas vezes com palavras que deixam de ser ditas e escritas. É por isso que a educação popular feita nas escolas do campo e indígenas ainda é pouco encontrada nos livros.

Conforme nos relatava um ancião e liderança indígenada aldeia Kayabi: "nosso livro é nossa aldeia" e, em complemento Arroyo (2012) afirma que: são outros sujeitos e outras pedagogias e, é por isso que a escola e a formação de professores devem ser também outras. Para essas outras 
pedagogias, que não as mesmas que "servem para todos" é necessária formação específica e, assim demanda-se um Cefapro e Secretarias com pessoas capacitadas e qualificadas para essas diversidades.

Trata-se de educações exigentes em todos os aspectos, inclusive para as comunidades camponesas e indígenas, pois, se elas se conformassem com o pouco ou com a educação invasora urbanocêntrica que thes era proporcionada, pareceria mais fácil, por se tratar de algo que existe como experiência. Mas, é isso mesmo que esses povos questionam e rejeitam em inúmeras lutas, desde as locais às regionais e nacionais. Esses povos estão dizendo que basta de serem tratados como resíduos e estorvos e, a educação pode e deve ser alavancadora de transformações.

As carências ainda existem enquanto materiais pedagógicos, falta de carteiras e cadeiras em número suficientes, iluminação apropriada, acesso a telefone e internet para facilitar a vida dos professores das escolas indígenas e de educação do campo. Diante disso, as comunidades se mobilizam constantemente para irem suprindo o que podem como sempre fizeram, mas, nas últimas duas décadas em especial, têm cobrado dos órgãos públicos para que a sua situação melhore.

As resistências continuam e tanto nas escolas do campo quanto nas indígenas há um sentimento de que não podem deixar cair por terra o que fora conquistado até aqui. De um lado afirmam que o Estado deve continuar presente diante de suas demandas, mas agora não no sentido colonialista, e, por outro, precisam ir exercendo a autonomia e a democracia que aprenderam thes pertencer. Essa confluência parece não ser entendida para os órgãos públicos ainda em muitas situações, e, se assim não for, a educação passa a ser esvaziada de sentido para as crianças, jovens, professores e lideranças dessas escolas.

Santos (2011) afirma que há uma linha abissal separando o nós - os bons e cultos - dos outros, os que nada sabem, os leigos e plebeus e, mais que separar, o abissal possui um sentido de negar enquanto existência. Contudo, nesse momento em que povos indígenas e populações camponesas, tratados como os outros, aprenderam que possuem direitos forjados por eles mesmos, é praticamente impossível tê-los como nulos, conforme já fora no passado. Eles e elas estão reivindicando o que o Estado os deve, e, por meio de educação específica se fazem fortalecidos em crenças, costumes, tradições, resistências e lutas. Nas palavras de Santos, a monocultura de saberes e ciência já não serve porque muitos povos descobriram que podem e, que a educação que fazem e defendem ajuda-Ihes a fortalecer o poder das comunidades.

Percebe-se que a educação do campo e a educação escolar indígena possuem sentido próprio, e, talvez só faça sentido para os povos que vivem essas realidades além de pessoas que buscam compreender e se somar a esse universo. Ainda há preconceito com essas populações assim como, com o que advém delas e, nesse caso é necessário desocultar e desacomodar a própria educação de que, se dita "para todos", todos devem fazer e compreender da mesma maneira. As vivências e experiências são outras nos territórios indígenas e camponeses, e, em razão disso, a educação pensada longe deles pouco lhes diz e muito lhes impõe. Manter as especificidades, mesmo com os muitos desafios é uma questão de direito, portanto, tem a ver com cumprimento de Lei no que tange a dignidade e ao respeito. 


\section{REFERÊNCIAS}

1. ARROYO, Miguel. Outros sujeitos, outras pedagogias. São Paulo: Vozes, 2012

2. BELLO, Álvaro. Etnicidad y ciudadanía en América Latina. Chile: Cepal, 2004.

3. BRANDÃO, Carlos Rodrigues. Educação popular. São Paulo: Brasiliense, 1984.

4. O ardil da ordem: Caminhos e armadilhas da educação popular. 2. ed. Campinas: Papirus, 1986. Educação como cultura. Campinas: Mercado das Letras, 2002. Ação Cultural para a Liberdade. SP: Paz e Terra, 2002.

; FAUNDEZ, Antonio. Por uma Pedagogia da Pergunta. RJ: Paz e Terra, 2002. ; BETTO, Frei. Essa escola chamada vida. SP: Ática, 2003. Política e Educação. SP: Cortez, 2003.

BRASIL. MINSTÉRIO DA EDUCAÇÃO E CULTURA. CÂMARA DE EDUCAÇÃO BÁSICA. Resolução 05/2012. Educação escolar indígena. Disponível em: <http://portal.mec.gov.br/index.php?option=com_docman\&view=download\&alias=11074-rceb00512-pdf\&category_slug=junho-2012-pdf\&Itemid=30192>. Acesso em 19 jun. 2017.

11. CALDART, Roseli Salete. Educação do campo. In: Dicionário da educação do campo. CALDART, Roseli Salete; PEREIRA, Isabel Brasil; ALENTEJANO, Paulo; FRIGOTTO, Gaudêncio (Orgs.). São Paulo: Expressão Popular, 2012. p. 257- 264.

12. CHARLOT, Bernard. Da relação com o saber às práticas educativas. São Paulo: Cortez, 2013.

13. CONTE, Isaura Isabel. $O$ processo educativo da luta e do trabalho das mulheres: Via Campesina no Brasil, UNORCA/UNMIC e COMAMI no México. (Tese). Doutorado em Educação. 196 p. Universidade Federal do Rio Grande do Sul, Porto Alegre, 2014.

14. FERREIRA, Waldineia Antunes Alcântara; PEREIRA, Lisanil da Conceição Patrocínio; JESUS, Lori Hack. Tecendo a rede: movimentos... trançados... nós, entre nós e conosco mesmo. In: GUIMARÃES et al. (Org.). Ruação: das epistemologias da rua à política da rua. Cuiabá: EdUFMT; Editora Sustentável, 2014. p. 253-266. 
15 desafios. Tese. (Doutorado em Educação). 180 f. Universidade Federal do Rio Grande do Sul. Porto Alegre (RS), 2014. práticas diversas, cimentadas por uma causa comum. Revista Diálogos. v. 18, n. 1. p. 10-32. Brasília. 2012.

17. IBGE. Notas técnicas. Histórico da investigação sobre cor ou raça nas pesquisas domiciliares do IBGE (2008). Disponível em: <http://www.ibge.gov.br/home/estatistica/populacao/caracteristicas_raciais/notas_tecnicas.pdf> Acesso em 10 jan. 2014. brasileira. 6. ed. São Paulo: Loyola, 2003.

PALUDO, Conceição. Educação popular em busca de alternativas. Uma leitura desde o campo democrático popular. Porto Alegre: Tomo Editorial, 2001.

PASSOS, Luiz Augusto. Cultura: Flecha humana e cósmica que aponta o caminho para os sentidos. In: GRANDO, Beleni Salete. PASSOS, Luiz Augusto. (Orgs). O eu e o outro na escola: contribuições para incluir a história e a cultura dos povos indígenas na escola. Cuiabá: EdUFMT, 2010. Humana. $\quad$ 5., $2013 . \quad$ Anais eletrônicos. Disponível em:<https://anaiscongressofenomenologia.fe.ufg.br/up/306/o/Luizpassos.pdf> Acesso em: $16 / 07 / 2017$.

PIMENTA, Selma Garrido. O estágio na formação de professores. Unidade teoria e prática? 5. ed. São Paulo: Cortez, 2002. 
SANTOS, Boaventura Sousa. Para além do pensamento abissal das linhas globais a uma ecologia de saberes. In: SANTOS, Boaventura Sousa; MENEZES, Maria Paula (Orgs.). Epistemologias do Sul. São Paulo: Cortez, 2010. p. 31- 83.

25

26 2016b.

27 SECCHI, Darci. Escolas indígenas em Mato Grosso, como são e para onde vão. Disponíve em<http://www.ufmt.br/revista/arquivo/rev12/escolas_indigenas_em_mato_groso.html>. Acesso em 19 nov. 2017.

A difícil democracia: reinventar as esquerdas. São Paulo: Boitempo, 2016a.

As bifurcações da ordem: revolução, cidade, campo e indignação. São Paulo: Cortez, Colégio de México, 1988.

29. WANDERLEY, Maria de Nazareth Baudel. Um saber necessário. Os estudos rurais no Brasil. Campinas, 2011.

\section{Isaura Isabel Conte}

Doutora em Educação pelo Programa de Pós-Graduação em Educação da Universidade Federal do Rio Grande do Sul (UFRGS). Universidade do Estado de Mato Grosso - Unemat - Mato Grosso Brasil

\section{Lisanil da Conceição Patrocínio Pereira}

Graduada em Geografia. Mestra e Doutora em Educação. Universidade do Estado de Mato Grosso Unemat - Mato Grosso - Brasil

\section{Amanda Pereira da Silva Azinari}

Pedagoga e Mestra em Educação pela Universidade do Estado de Mato Grosso (Unemat). Universidade do Estado de Mato Grosso - Unemat - Mato Grosso - Brasil

\section{Como citar este documento}

CONTE, Isaura Isabel; PEREIRA, Lisanil da Conceição Patrocínio; AZINARI, Amanda Pereira da Silva. Educação ao revés: indígenas e camponeses mato-grossenses. Reflexão e Ação, Santa Cruz do Sul, v. 28, n. 1 , jan. 2020. ISSN 1982-9949. Disponível em: <https://online.unisc.br/seer/index.php/reflex/article/view/11359>. Acesso em: doi:https://doi.org/10.17058/rea.v28i1.11359. 